DOI 10.22460/jpmi.v1i3.435-444

\title{
PENGARUH SELF EFFICACY TERHADAP KEMAMPUAN BERPIKIR KRITIS MATEMATIK SISWA SMP
}

\author{
Laela Vina Hari ${ }^{1}$, Luvy Sylviana Zanthy ${ }^{2}$, Heris Hendriana ${ }^{3}$ \\ 1,2,3 IKIP Siliwangi, Jln Terusan Jendral Sudirman Cimahi, Jawa Barat, Indonesia \\ ${ }^{1}$ laelavina@gmail.com, ${ }^{2}$ zanthyluvy@ikipsiliwangi.ac.id, ${ }^{3}$ herishen@ikipsiliwangi.ac.id
}

Diterima: 14 Mei 2018; Disetujui: 28 Mei 2018

\begin{abstract}
The purpose of this research is to analyze and examine in depth about the influence of self-efficacy on the ability to think critically mathematically of junior high school students. The research method used in this research is the correlational method with the quantitative approach using simple of 30 students of junior high school class VIII in one of junior high school in West Bandung Regency with high, medium, and low ability student classification. The instrument used consisted of the test of critical thinking ability of mathematics as much as 7 item and non-test in the form of the self-efficacy scale as many as 24 statement. The results of this study indicate that the ability to think critically mathematically junior high school students are positively influenced by self-efficacy amount 56,4 \% and influenced by other factors of students self-efficacy amount 43,6\%.
\end{abstract}

Keywords: Mathematical Critical Thinking, Self-efficacy

\begin{abstract}
Abstrak
Tujuan penelitian ini untuk menganalisis dan menelaah secara mendalam tentang pengaruh self efficacy terhadap kemampuan berpikir kritis matematik siswa SMP. Metode penelitian yang digunakan dalam penelitian ini adalah metode korelasional dengan pendekatan kuantitatif menggunakan sampel sebanyak 30 siswa SMP kelas VIII pada salah satu SMP di Kabupaten Bandung Barat dengan klasifikasi siswa kemampuan tinggi, sedang dan rendah. Instrumen yang digunakan terdiri dari tes kemampuan berpikir kritis matematik sebanyak 7 butir soal dan non tes berupa skala self efficacy sebanyak 24 pernyataan. Hasil penelitian ini menunjukkan bahwa kemampuan berpikir kritis matematik siswa SMP dipengaruhi positif oleh self efficacy sebesar 56,4 \% dan dipengaruhi oleh faktor lain dari self efficacy siswa sebesar 43,6\%.
\end{abstract}

Kata Kunci: Berpikir Kritis Matematis, Self-efficacy

How to cite: Hari, L. V., Zanthy, L. S., \& Hendriana, H. (2008). Pengaruh Self Efficacy terhadap Kemampuan Berpikir Kritis Matematik Siswa SMP. JPMI - Jurnal Pembelajaran Matematika Inovatif, 1 (3), 435-444.

\section{PENDAHULUAN}

Kemampuan berpikir kritis merupakan salah satu komponen kognitif peserta didik yang menunjang keberhasilan mereka dalam proses pembelajaran. Meskipun demikian, berpikir kritis cenderung jarang diperhatikan dalam pembelajaran matematika. Ennis (Hidayat, 2011; 2012) mengungkapkan bahwa "berpikir kritis matematik adalah suatu proses berpikir dengan tujuan mengambil keputusan yang masuk akal tentang apa yang diyakini berupa kebenaran yang dapat dilakukan dengan benar". Kemampuan berpikir kritis matematik adalah salah satu cara berpikir tingkat tinggi siswa yang diukur meliputi enam unsur menurut Ennis (Hidayat, 
2011; 2012) yaitu fokus, reason (alasan), inference (simpulan), situasion (situasi), clarity (kejelasan) dan overview (pandangan menyeluruh).

Berpikir kritis merupakan bagian penting dari tujuan pembelajaran matematika. Hal ini dapat dilihat dari tujuan Permendiknas No. 22 tahun 2006 dalam matematika di sekolah yang menekankan siswa supaya memiliki kemampuan: (1) memahami konsep matematika dalam menjelaskan keterkaitan antarkonsep dan mengaplikasikan konsep atau algoritma secara luwes, akurat, efisien, dan tepat dalam pemecahan masalah; (2) menggunakan penalaran pada pola dan sifat, melakukan manipulai matematika dalam membuat generalisasi, menyu sun bukti, atau menjelaskan gagasan dan pernyataan matematika seperti berpikir logis, kritis, sistematis, jujur, dan disiplin dalam menyelesaikan masalah; (3) memecahkan masalah yang meliputi kemampuan memahami masalah, menyelesaikan model dan menafsirkan solusi yang diperoleh; dan (4) mengkomunikasikan suatu gagasan dengan simbol, tabel, diagram, atau media lain untuk memperjelas keadaan atau masalah. Sebagaimana yang sudah tertera pada poin ke 2, bahwa dengan berpikir kritis siswa dituntut untuk memahami serta mempelajari matematika dengan benar agar pengetahuan siswa berkembang dan tidak hanya berpusat pada penjelasan yang diberikan oleh guru dan buku sumber yang dimiliki siswa. Sejalan dengan Zanthy (2016) mengungkapkan bahwa "berpikir kritis sangat diperlukan oleh setiap orang untuk menyikapi berbagai permasalahan dalam realita kehidupan, dengan berpikir kritis seseorang dapat mengatur, menyesuaikan, atau mengubah pola pikirnya, sehingga dapat memutuskan suatu tindakan yang tepat".

Kenyataannya pada saat ini proses pembelajaran matematika yang dilaksanakan di kebanyakan sekolah masih mengalami kesulitan untuk mencapai kompetensi kemampuan berpikir matematik. Berdasarkan hasil laporan TIMSS 2011 Provasnik menunjukkan bahwa siswa kelas VIII di Indonesia menempati posisi ke 38 diantara 42 negara yang berpartisipasi dalam tes matematika dari skor rata-rata berpikir kritis matematik. Hal ini merupakan bukti nyata dilapangan yang dimana kemampuan berpikir kritis matematik masih rendah, dikarenakan siswa masih cenderung belum berhasil menjawab soal-soal permasalahan non rutin yang diberikan dengan benar. Selain itu siswa juga sering mengalami kesulitan dalam menyelesaikan masalah yang menuntut siswa harus berpikir kritis, dikarenakan siswa jarang dilatih bagaimana menyelesaikan soal yang memerlukan kemampuan berpikir kritis. Maka hal tersebut sejalan dengan pendapat Tresnawati, Hidayat, \& Rohaeti (2017) bahwa siswa dalam menyelesaikan soal-soal berpikir kritis matematik masih mengalami terdapat kesulitan terhadap beberapa indikator dalam menganalisis suatu pertanyaan, jawaban, argumen yang relevan dan memeriksa kembali suatu pernyataan atau proses yang bisa dikatakan masih belum bisa membuktikan hasil yang benar atau salah.

Hidayat (2017) menyatakan bahwa kemampuan afektif dapat menentukan keberhasilan belajar seseorang. Dalam mengembangkan kemampuan matematika khususnya kemampuan berpikir kritis diperlukan sebuah aspek penting yang harus dimiliki oleh setiap perserta didik yaitu sikap yakin dan percaya akan kemampuan sendiri agar terhindar dari rasa cemas dan ragu, yang dimana sikap tersebut dapat diartikan sebagai daya juang seseorang yang lemah dalam memecahkan masalah sehingga akan memperoleh hasil yang tidak optimal (Dilla, Hidayat, \& Rohaeti, 2018; Rahmi, Nadia, Hasibah, \& Hidayat, 2017; Sumarmo, Mulyani, \& Hidayat, 2018; Tresnawati, Hidayat, \& Rohaeti, 2017). Menurut Bandura (Warsito, 2009) mengungkapkan bahwa self efficacy adalah suatu keyakinan individu bahwa dirinya mampu untuk melakukan sesuatu dalam situasi tertentu dengan berhasil. Hal ini tentu akan mengakibatkan bagaimana individu merasa berpikir dan bersikap (keputusan yang dipilih, usaha yang dilakukan dan keteguhannya pada saat menghadapi hambatan), memiliki rasa 
bahwa individu mampu untuk mengendalikan lingkungan sosialnya. Self efficacy sangat mempengaruhi apa yang dilakukan siswa. Siswa yang tidak mau berusaha, tercapainya kemampuan berpikir kritis matematik tidaklah mudah. Hal ini mengakibatkan banyaknya siswa yang akhirnya terbiasa mencontek atau mengandalkan orang lain untuk menyelesaikan permasalahan yang dihadapi karena tidak yakin akan kemampuannya sendiri, akibatnya siswa tidak dapat menyelesaikan soal-soal berpikir kritis matematik dengan tepat.

Menyikapi hal tersebut, maka perlu dilakukan penelitian yang menjadi urgensi dari permasalahan tentang seberapa besar pengaruh self efficacy terhadap kemampuan berpikir kritis matematik siswa.

\section{METODE}

Metode dalam penelitian ini menggunakan metode korelasional dengan pendekatan kuantitatif yang bertujuan untuk mengetahui dengan menganalisis dan menelaah secara mendalam tentang pengaruh self efficacy terhadap kemampuan berpikir kritis matematik siswa SMP pada materi lingkaran. Populasi dalam penelitian ini adalah seluruh siswa kelas VIII SMP di Kabupaten Bandung Barat dan menggunakan sampel sebanyak 30 siswa SMP kelas VIII pada salah satu SMP di Kabupaten Bandung Barat dengan klasifikasi siswa kemampuan tinggi, sedang dan rendah. Instrumen dalam penelitian ini menggunakan tes dan non tes. Instrumen tes tersebut didasarkan pada penilaian terhadap kemampuan berpikir kritis matematik, sedangkan instrumen non tes didasarkan pada penilaian terhadap self efficacy siswa. Tes kemampuan berpikir kritis matematik sebanyak 7 butir soal dan non tes berupa skala self efficacy siswa sebanyak 24 pernyataan. Data hasil penelitian akan diolah dan dianalisis pengujian normalitas data dan uji linearitas terlebih dahulu dalam menentukan uji statistika regresi.

Adapun contoh instrumen tes dan non tes secara berurutan disajikan pada gambar 1 dan 2 berikut ini.

Terdapat 3 buah lingkaran yang memiliki luas masing-masing adalah
$616 \mathrm{~cm}^{2}, 2.464 \mathrm{~cm}^{2}$, dan $5.544 \mathrm{~cm}^{2}$. Coba bandingkan berdasarkan jari-jari dan keliling
masing-masing lingkaran tersebut, apa yang dapat kamu simpulkan!

Berikut ini diberikan gambar dua persegi dengan ukuran yang sama. Di dalam persegi tersebut dibuat lingkaran sesuai dengan gambar berikut. Panjang sisi gambar A adalah bilangan genap dan sisi gambar B adalah bilangan ganjil, dan perbandingan panjang sisi persegi tersebut $2: 1$. Gambar manakah yang mempunyai daerah arsiran yang terluas? Hitunglah dan berikan alasanmu.

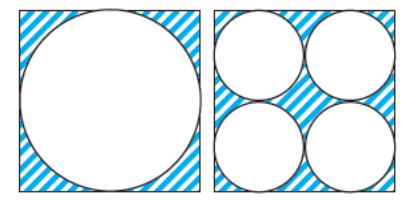

A

B

Gambar 1. Instrumen tes tentang kemampuan berpikir kritis matematik siswa 


\begin{tabular}{|c|c|c|c|c|c|c|c|}
\hline \multicolumn{8}{|c|}{ SKALA SELF EFFICACY SISWA } \\
\hline \multicolumn{8}{|c|}{ Keterangan: } \\
\hline \multicolumn{2}{|r|}{ SS : Sangat Sering } & S : Sering & JR : Jarang & \multicolumn{4}{|c|}{ JS : Jarang Sekali } \\
\hline \multirow{2}{*}{ No } & \multirow{2}{*}{\multicolumn{2}{|c|}{ Pernyataan }} & & \multicolumn{4}{|c|}{ Respon } \\
\hline & & & & SS & $\mathbf{S}$ & $\mathbf{J R}$ & $\mathbf{J S}$ \\
\hline 1. & $\begin{array}{l}\text { Saya yakin saya b } \\
\text { mengenai materi } 1 \\
\text { berusaha. }\end{array}$ & $\begin{array}{l}\text { yelesaikan } \\
\text { n sesulit ap }\end{array}$ & $\begin{array}{l}\text { matematika } \\
\text { dengan }\end{array}$ & & & & \\
\hline 2. & $\begin{array}{l}\text { Saya yakin akan b } \\
\text { lingkaran yang ak }\end{array}$ & $\begin{array}{l}\text { dalam ulang } \\
\text { datang. }\end{array}$ & ateri & & & & \\
\hline 3. & $\begin{array}{l}\text { Mempelajari tuga } \\
\text { hal yang mencem }\end{array}$ & lingkaran y & oaru adalah & & & & \\
\hline 4. & $\begin{array}{l}\text { Saya bersedia ditu } \\
\text { matematika. }\end{array}$ & agai ketua & apok & & & & \\
\hline
\end{tabular}

Gambar 2. Instrumen non tes tentang self efficacy siswa

\section{HASIL DAN PEMBAHASAN}

\section{Hasil}

Berdasarkan hasil analisis data, berikut ini adalah rangkuman hasil perhitungan uji normalitas kedua variabel yaitu self efficacy dan kemampuan berpikir kritis matematik siswa yang disajikan pada tabel 1 berikut.

Tabel 1. Uji Normalitas antara Self Efficacy dan Kemampuan Berpikir Kritis Matematik

\begin{tabular}{lcccccc}
\hline & \multicolumn{2}{c}{ Kolmogorov-Smirnov $^{\text {a }}$} & \multicolumn{3}{c}{ Shapiro-Wilk } \\
& Statistic & Df & Sig. & Statistic & df & Sig. \\
\hline Self Efficacy & 0,088 & 30 & 0,200 & 0,968 & 30 & 0,481 \\
Kemampuan Berpikir & 0,147 & 30 & 0,095 & 0,899 & 30 & 0,008 \\
Kritis & & & & & & \\
\hline
\end{tabular}

*. This is a lower bound of the true significance.

a. Lilliefors Significance Correction

Berdasarkan Tabel 1 terlihat bahwa nilai signifikan kedua variabel > 0,05 maka Ho diterima artinya sampel yang digunakan berdistribusi normal. Selanjutnya dilakukan uji linearitas self efficacy terhadap kemampuan berpikir kritis matematik siswa dengan hasil pengujian disajikan pada Tabel 2 berikut. 
Tabel 2. Uji Linearitas antara Self Efficacy dan Kemampuan Berpikir Kritis

\begin{tabular}{|c|c|c|c|c|c|c|}
\hline & & $\begin{array}{l}\text { Sum of } \\
\text { Squares }\end{array}$ & $d f$ & $\begin{array}{c}\text { Mean } \\
\text { Square }\end{array}$ & $\boldsymbol{F}$ & Sig. \\
\hline \multirow{2}{*}{$\overline{\text { Self Efficacy }}$} & Between (Combined) & 195,252 & 4 & 48,813 & 8,421 & 0,000 \\
\hline & Groups Linearity & 191,781 & 1 & 191,781 & 33,085 & 0,000 \\
\hline \multirow{3}{*}{$\begin{array}{l}\text { Kemampuan } \\
\text { Berpikir } \\
\text { Kritis }\end{array}$} & Deviation from Linearity & 3,472 & 3 & 1,157 & 0,200 & 0,896 \\
\hline & Within Groups & 144,914 & 25 & 5,797 & & \\
\hline & Total & 340,167 & 29 & & & \\
\hline
\end{tabular}

Berdasarkan hasil uji linearitas pada Tabel 2 antara self efficacy dan kemampuan berpikir kritis matematik siswa SMP diperoleh nilai $F_{\text {hitung }}$ untuk uji linearitas sebesar 0,200 dan P value sebesar 0,896 dengan nilai sig. 0,000 maka terlihat bahwa terdapat hubungan linaear yang kuat. Hal ini dikarenakan nilai sig. Dari Deviation from Linearity menghasilkan nilai 0,896 yang berarti nilai Sig. $>\alpha=5 \%$.

Ketika sudah melakukan pengujian normalitas data dan uji linearitas maka dilakukan uji statistika regresi untuk dapat melihat apakah terdapat pengaruh dari self efficacy siswa terhadap kemampuan berpikir kritis matematik dengan hasil pengujian disajikan pada Tabel 3, 4 dan 5 berikut.

Tabel 3. Uji Regresi antara Self Efficacy dan Kemampuan Berpikir Kritis (Uji F)

\begin{tabular}{llccccc}
\hline & & Sum of & & & & \\
& Model & Squares & Df & Mean Square & F & Sig. \\
\hline 1 & Regression & 191,781 & 1 & 191,781 & 36,188 & $0,000^{b}$ \\
& Residual & 148,386 & 28 & 5,300 & & \\
& Total & 340,167 & 29 & & & \\
\hline
\end{tabular}

a. Dependent Variable: Self efficacy

b. Predictors: (Constant), Kemampuan Berpikir Kritis

Tabel 4. Model Summary

\begin{tabular}{ccccc}
\hline Model & R & R Square & $\begin{array}{c}\text { Adjusted R } \\
\text { Square }\end{array}$ & $\begin{array}{c}\text { Std. Error of the } \\
\text { Estimate }\end{array}$ \\
\hline 1 & $0,751^{\mathrm{a}}$ & 0,564 & 0,548 & 2,30206 \\
\hline
\end{tabular}

a. Predictors: (constans), Self efficacy

Berdasarkan hasil uji regresi pada Tabel 3 dan 4. Diketahui nilai Signifikansi untuk pengaruh self efficacy siswa secara simultan terhadap kemampuan berpikir kritis matematik adalah nilai Sig. sebesar 0,000 dan nilai Fhitung 191,781 > F tabel 36,188 sehingga dapat disimpulkan bahwa terdapat pengaruh self efficacy siswa secara simultan terhadap kemampuan berpikir kritis matematik pada taraf signifikasi 5\%. Selain itu besarnya koefisien korelasi (R) adalah 0,751 dan nilai koefisien determinasi ( $R$ square) sebesar 0,564 . Hal ini dapat diartikan bahwa 
pengaruh self efficacy siswa secara simultan terhadap kemampuan berpikir kritis matematik siswa adalah sebesar 56,4 \% sedangkan $43,6 \%$ dipengaruhi oleh faktor lain di luar self efficacy siswa.

Menurut Suharsimi (2010) Regresi ganda (multiple regression) adalah suatu perluasan dari teknik regresi apabila terdapat lebih dari satu variabel bebas untuk mengadakan prediksi terhadap variabel terkait. Rumus persamaannya menurut Sugiyono (2013) adalah sebagai berikut: $Y=a+b_{1} X_{1}+b_{2} X_{2}+\ldots b_{n} X_{n}$. Untuk melihat persamaan regresi dari hasil pengujian tentang pengaruh self efficacy siswa terhadap kemampuan berpikir kritis matematik siswa dilihat dari Tabel 5.

Tabel 5. Uji Parsial $(\mathrm{Uji}-\mathrm{t})$

\begin{tabular}{|c|c|c|c|c|c|c|}
\hline & \multirow[t]{2}{*}{ Model } & \multicolumn{2}{|c|}{$\begin{array}{l}\text { Unstandardized } \\
\text { Coefficients }\end{array}$} & \multirow{2}{*}{$\begin{array}{c}\text { Standardized } \\
\text { Coefficients } \\
\text { Beta } \\
\end{array}$} & \multirow[t]{2}{*}{$\mathbf{t}$} & \multirow[t]{2}{*}{ Sig. } \\
\hline & & B & Std. Error & & & \\
\hline \multirow[t]{2}{*}{$\overline{1}$} & (Constant) & 36,103 & 8,277 & & 4,362 & 0,000 \\
\hline & $\begin{array}{l}\text { Kemampuan Berpikir } \\
\text { Kritis }\end{array}$ & 1,896 & 0,315 & 0,751 & 6,016 & 0,000 \\
\hline
\end{tabular}

a. Dependent Variable: Self Efficacy

Pada tabel 5 tersebut diperoleh nilai $\mathrm{a}=36,103$ dan $\mathrm{b}=1,896$ sehingga didapat persamaan regresi dari hasil pengujian tentang pengaruh self efficacy terhadap kemampuan berpikir kritis matematik siswa adalah sebagai berikut:

$\mathrm{Y}=36,103+1,896 \mathrm{X}$

Hal ini dapat diinterpretasikan bahwa apabila self efficacy siswa bernilai 0 (nol), maka kemampuan berpikir kritis matematik siswa bernilai 36,103 dan terlihat pula bahwa koefisien dari self efficacy siswa bernilai positif artinya terdapat pengaruh yang positif antara self efficacy terhadap kemampuan berpikir kritis matematik siswa. Sehingga dapat disimpulkan bahwa semakin tinggi self efficacy yang dimiliki oleh siswa, maka akan semakin tinggi pula kemampuan berpikir kritis matematik siswa tersebut.

\section{Pembahasan}

Dari hasil analisis data penelitian terlihat bahwa terdapat pengaruh positif antara self efficacy terhadap kemampuan berpikir kritis mamematik siswa SMP. Artinya semakin tinggi self efficacy siswa maka akan semakin tinggi pula kemampuan berpikir kritis matematik siswa, karena siswa yang memiliki self efficacy yang tinggi dalam matematika cenderung lebih kritis yaitu memiliki ide yang banyak dan lebih berani dalam mengambil keputusan untuk menyelesaikan permasalahan yang ada serta dapat memberikan penjelasan terhadap apa yang sudah dibuktikan.

Selain itu, untuk siswa yang memiliki sikap self efficacy kurang dalam matematika akan cenderung mengerjakan penyelesaian soal dengan seadanya sesuai dengan pengetahuan yang diperoleh, tidak adanya keingin diri untuk mengekspolari. Mengikuti prosedur pada umumnya dan lebih mengandalkan hapalan, sehingga siswa tersebut menjadi lemah dalam pengambilan keputusan saat proses penyelesaian masalah yang dialaminya. 
Berikut hasil pekerjaan siswa dengan sikap self efficacy dalam matematika yang disajikan pada gambar 1 dan 2.
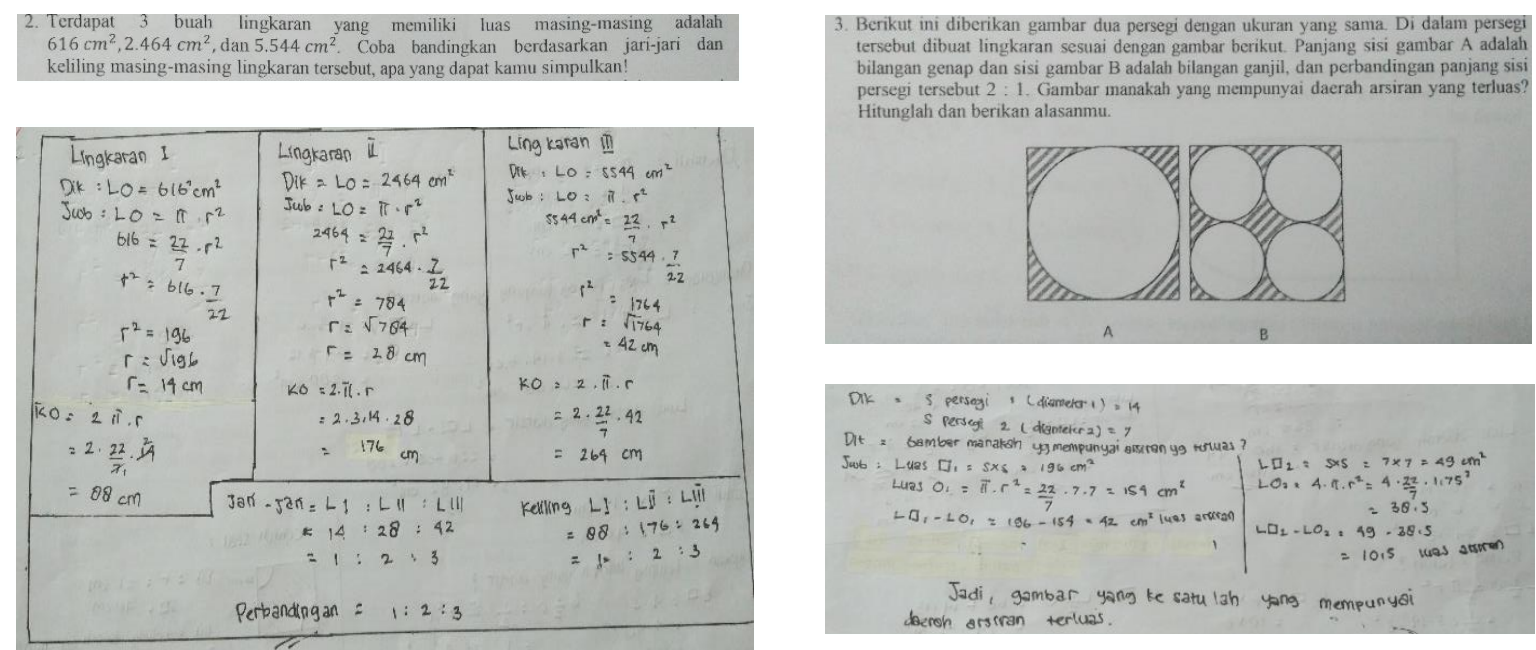

Gambar 1. Hasil pekerjaan siswa dengan sikap self efficacy yang baik

Pada gambar 1 terlihat bahwa hasil pekerjaan siswa yang melakukan langkah pembuktian langsung mengenai materi lingkaran. Hal ini siswa mencari penyelesaian dari permasalahan tersebut untuk menghasilkan solusi penyelesaian yang sama dengan keterangan yang sudah diberikan. Selain itu, ide awal dan strategi penyelesaian yang diambil oleh siswa tersebut sudah dianggap tepat dan jelas, walaupun pada akhirnya siswa tersebut melakukan pemeriksaan kembali dari hasil penyelesaian yang dia berikan agar sesuai dengan keputusan yang sudah mereka kerjakan. Hal ini sejalan dengan penelitian Kusdinar, dkk (2017) yang berpendapat bahwa "dalam proses membuktikan suatu permasalahan, diperlukan kemampuan siswa mulai dari merumuskan ide awal dan menyusun strategi penyelesaian".
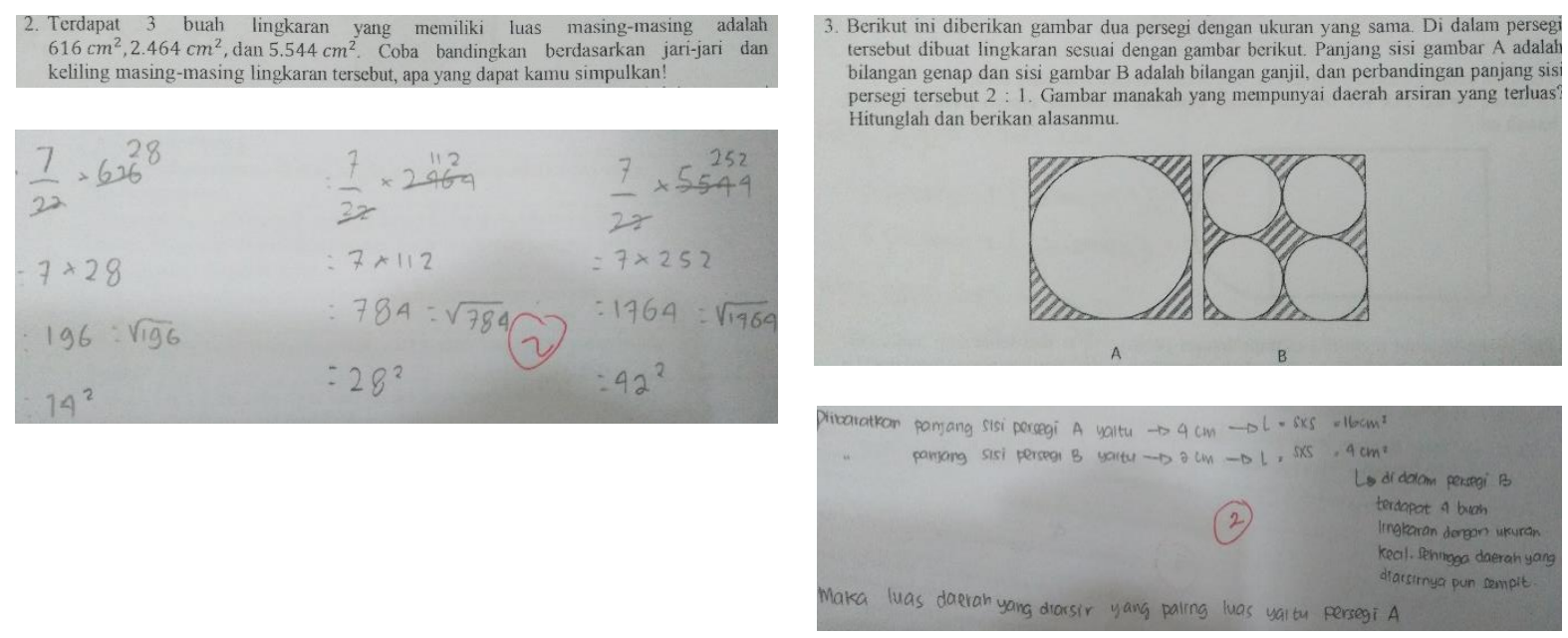

Gambar 2. Hasil pekerjaan siswa dengan sikap self efficacy yang kurang baik 
Pada gambar 2 bahwa hasil pekerjaan siswa yang melakukan langkah pembuktian langsung mengenai materi lingkaran. Hal ini terlihat bahwa siswa tersebut memaksakan jawaban agar benar sesuai dengan keterangan yang ada tanpa melakukan ide awal terlebih dahulu dalam membuat suatu simpulan yang jelas, sehingga terlihat ketidakyakinan siswa terhadap kemampuannya sendiri sehingga jawaban yang dihasilkan salah. Hasil pekerjaan siswa tersebut menunjukan tidak adanya kepercayaan diri dan kurangnya kemampuan terhadap materi tersebut. Dengan kurangnya self efficacy yang dimiliki akhirnya siswa tidak terpacu untuk mengeksplor dan berpikir kritis mencari banyak altenatif penyelesaian dengan benar dan jelas. Dengan kata lain siswa tersebut sudah menyerah ketika mengerjakan masalah diakibatkan daya juang dalam menghadapi masalah yang sangat lemah. Hal ini dikarenakan bahwa siswa yang memiliki sikap dengan daya juang yang lemah dalam menghadapi masalah akan mengakibatkan hasil yang tidak optimal, sehingga pada akhirnya tidak dapat menyelesaikan permasalahan yang sedang dihadapi. Sejalan dengan pendapat Sumarmo, Hidayat, Zukarnaen, Hamidah, \& Sariningsih (2012) bahwa kesulitan lain yang dialami siswa dalam menyelesaikan soal berpikir kritis adalah mengidentifikasi data yang tidak relevan dalam suatu kasus, sedangkan tugas yang relatif mudah adalah tugas menganalisa kebenaran suatu pernyataan, mengidentifikasi asumsi, dan menentukan peluang suatu kejadian.

Berkaitan dengan hasil penelitian yang menunjukkan bahwa kemampuan berpikir kritis matematik dipengaruhi self efficacy siswa terhadap suatu permasalahan, Hal ini telah diinterpretasikan bahwa jika self efficacy siswa bernilai 0 (nol), maka kemampuan berpikir kritis matematik siswa bernilai 36,103. Seperti pada Gambar 2 siswa yang tidak memiliki self efficacy maka kemampuan berpikir kritisnya masih kurang. Selain itu terlihat pula bahwa koefisien dari persamaan regresi bernilai positif yaitu $36,103+1,896 \mathrm{X}$ artinya terdapat pengaruh yang positif antara self efficacy terhadap kemampuan berpikir kritis matematik siswa. Ini ditunjukkan pada Gambar 1. jika siswa yang memiliki self efficacy tinggi, maka siswa tersebut mampu menyelesaikan soal dengan cara yang kritis yaitu tepat dan jelas. Kemampuan berpikir kritis matematik siswa SMP dipengaruhi positif oleh self efficacy 56,4\% dan 43,4\% dipengaruhi oleh faktor lain dari self efficacy. Sehingga dapat disimpulkan bahwa semakin tinggi self efficacy yang dimiliki siswa, maka akan semakin tinggi pula kemampuan berpikir kritis matematik siswa tersebut.

\section{KESIMPULAN}

Berdasarkan hasil analisis data dan pembahasan yang telah disajikan, maka dapat disimpulkan bahwa pengaruh self efficacy terhadap kemampuan berpikir kritis matematik siswa SMP dipengaruhi positif oleh self efficacy sebesar 56,4\%, sedangkan 43,6\% dipengaruhi oleh faktor selain self efficacy siswa.

\section{DAFTAR PUSTAKA}

Dilla, S. C., Hidayat, W., \& Rohaeti, E. E. (2018). Faktor Gender dan Resiliensi dalam Pencapaian Kemampuan Berpikir Kreatif Matematis Siswa SMA. Journal of Medives, 2(1), 129-136.

Hidayat, W. (2011). Meningkatkan Kemampuan Berpikir Kritis dan Kreatif Matematik Siswa Melalui Pembelajaran Kooperatif Think-Talk-Write (TTW) (Doctoral dissertation, Universitas Pendidikan Indonesia).

Hidayat, W. (2012). Meningkatkan Kemampuan Berpikir Kritis dan Kreatif Matematik Siswa 
SMA Melalui Pembelajaran Kooperatif Think-Talk-Write (TTW). In Seminar Nasional Penelitian, Pendidikan dan Penerapan MIPA.

Kusdinar, U., Sukestiyarno, S., Isnarto, I., \& Istiandaru, A. (2017). Krulik And Rudnik Model Heuristic Strategy In Mathematics Problem Solving. International Journal On Emerging Mathematics Education, 1(2), 205-210.

Rahmi, S., Nadia, R., Hasibah, B., \& Hidayat, W. (2017). The Relation between Self-Efficacy toward Math with the Math Communication Competence. Infinity Journal, 6(2), 177182.

Sugiyono. (2013). Metode Penelitian Pendidikan (Pendekatan Kuantitatif, Kualitatif Dan $R \& D)$. Bandung: Alfabeta.

Suharsimi, A. (2010). Prosedur Penelitian Suatu Pendekatan Praktik. Jakarta: Rineka Cipta.

Sumarmo, U., Hidayat, W., Zukarnaen, R., Hamidah, M., \& Sariningsih, R. (2012). Kemampuan dan Disposisi Berpikir Logis, Kritis, dan Kreatif Matematik (Eksperimen terhadap Siswa SMA Menggunakan Pembelajaran Berbasis Masalah dan Strategi ThinkTalk-Write). Jurnal Pengajaran MIPA, 17(1), 17-33.

Sumarmo, U., Mulyani, E., \& Hidayat, W. (2018). Mathematical Communication Ability and Self Confidence Experiment with Eleventh Grade Students Using Scientific Approach. JIML-Journal of Innovative Mathematics Learning, 1(1), 19-30.

Tresnawati, T., Hidayat, W., \& Rohaeti, E. E. (2017). Kemampuan Berpikir Kritis Matematis dan Kepercayaan Diri Siswa SMA. Symmetry: Pasundan Journal of Research in Mathematics Learning and Education, 2(2), 39-45.

Warsito, H. (2009). Hubungan Antara Self-Efficacy Dengan Penyesuaian Akademik Dan Prestasi Akademik. Jurnal Ilmiah Ilmu Pendidikan, Ix(1), 29-47.

Zanthy, L. S. (2016). Pengaruh Motivasi Belajar ditinjau dari Latar Belakang Pilihan Jurusan Terhadap Kemampuan Berpikir Kritis Mahasiswa di STKIP Siliwangi Bandung. Teori dan Riset Matematika, 1(1), 47-54. 
444 Hari, Zanthy, \& Hendriana, Pengaruh Self Efficacy terhadap Kemampuan Berpikir Kritis ... 